\title{
Vulvar Cancer pNO TNM Finding v7
}

National Cancer Institute

\section{Source}

National Cancer Institute. Vulvar Cancer pNO TNM Finding v7. NCI Thesaurus. Code C89429.

Vulvar cancer without regional lymph node metastasis. (from AJCC 7th Ed.) 